\title{
Crossed non-dominant hemisphere syndrome in a right-hander
}

\author{
M. Fujimori ${ }^{1}$, K. Wakisaka ${ }^{1}$, A. Yamadori ${ }^{3}$, T. Imamura ${ }^{3}$, T. Uehara ${ }^{2}$, K. Yamashita ${ }^{1}$ \\ and M. Tabuchi ${ }^{2}$
}

${ }^{1}$ Neuropsychology and ${ }^{2}$ Neurology Service, Hyogo Brain and Heart Center at Himeji, 520 , Saisho-Ko,Himeji 670, and ${ }^{3}$ Hyogo Institute for Aging Brain and Cognitive Disorders, Himeji, Japan

Correspondence to: M. Fujimori Division of Neuropsychology, Hyogo Institute for Aging Brain and Cognitive Disorders, 520, Saisho-Ko, Himeji 670, Japan

\begin{abstract}
A right-handed patient with a large left temporo-parietal infarction manifested various non-dominant hemisphere signs. He had two left-handed children. On neurobehavioural examinations, he did not show aphasia or ideomotor apraxia, but did show hemispatial neglect, spatial agraphia, constructional apraxia, auditory and tactile extinction, anosodiaphoria and affective changes, all of which are usually observed after right hemispheric damage. We conclude that he has a reversed cerebral laterality of cognitive functions and showed crossed non-dominant hemisphere syndrome.
\end{abstract}

Keywords: Cerebral laterality - Handedness - Right hemisphere syndrome

\section{INTRODUCTION}

Injury of the right hemisphere may cause left hemispatial neglect, constructional apraxia, extinction on double-simultaneous stimulation, motor impersistence, anosognosia or prosopagnosia (Hier et al., 1983). Other studies have reported that spatial agraphia (Hécaen and Marcie, 1974), acute confusional state (Mesulam et al., 1976; Mori and Yamadori, 1987) or affective deficits (Gainotti, 1989) occur after right hemispheric damage. These neurobehavioural abnormalities (non-dominant hemisphere syndrome) may be seen in left-sided injuries if cerebral laterality of cognitive function is reversed.

In several case reports, lesion in the left hemisphere was associated with normal language functions and visuospatial deficits (Taylor and Solomon, 1979; Kellar and Levick, 1985; Junqué et al., 1986; Caramazza and Hills, 1990; Maeshima et al., 1992), but the authors did not mention most of the other signs. We here report a patient with a large left temporoparietal infarction who manifested various non-dominant hemisphere signs.

\section{CASE REPORT}

A 53-year-old male university graduate was referred to our neuropsychology section for evaluation 2 months after an ischaemic stroke. He had been the director of a driving school but retired after the stroke. He reported himself as a definite right-hander, that is, before the stroke he had always used the right hand for writing, drawing, throwing, brushing his teeth, cutting with scissors and eating with chopsticks. He had two right-handed and two left-handed children. A neurological examination revealed a right hemiparesis and a right homonymous hemianopsia. A cranial computed tomogram (CT) showed a left temporo-parietal infarction. In brief neuropsychological assessment, there were no signs of aphasia but he showed spatial distortion in writing and right-sided hemineglect in copying a transparent cube.

$\mathrm{He}$ was admitted to our hospital 5 years later, because of an episode of falling, and we had a chance to re-examine him. His wife reported that his inattention to the right side had been unchanged for 5 years, and he repeatedly hit his right limbs. His neurological state was unchanged, and routine laboratory findings were normal. Magnetic resonance imaging (MRI) of the head delineated the old infarction but revealed no new lesions (Fig. 1).

He was awake and cooperative during the assessment. His digit span was five forward, two backward, and he scored 23 in the Mini-Mental State Examination (MMSE). The Wechsler Adult Intelligent Scale-Revised (WAIS-R) showed verbal IQ of 76. 


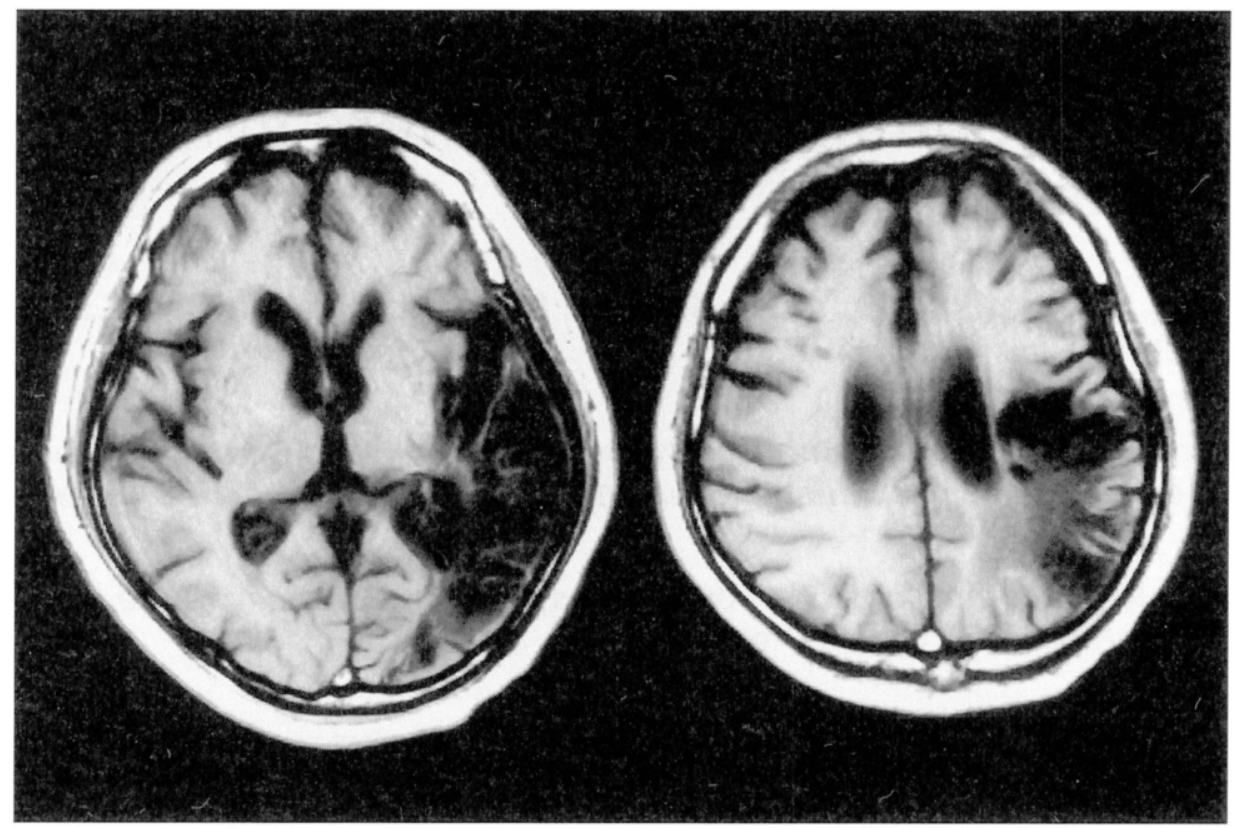

FIG. 1. Cranial magnetic resonance T1-weighted images 5 years after onset demonstrated a left temoro-parietal infarction.

TABLE I. The patient's scores in the subtests in the Western Aphasia Battery

\begin{tabular}{lr}
\hline Spontaneous speech & $19 / 20$ \\
Auditory comprehension & $9.5 / 10$ \\
Repetition & $10 / 10$ \\
Naming & $8.4 / 10$ \\
Reading & $7.4 / 10$ \\
Writing & $1.2 / 10$ \\
\hline
\end{tabular}

His running speech was fluent without paraphasia, articulatory disturbance or dysprosody. Repetition, confrontation naming and auditory comprehension were all normal. Comprehension of written words was preserved, but he tended to neglect right-sided words in reading sentences. His writing, performed with the left hand, consisted of distorted letters, occasional stroke omissions and slanted lines, with no signs of aphasic dysgraphia. Thus, he had spatial agraphia (Hécaen and Marcie, 1974). Table I shows the scores of subtests in the Western Aphasia Battery (WAB). There was no buccofacial or ideomotor apraxia.

Many non-dominant hemisphere signs were present. We observed right hemineglect in line bisection, line cancellation, copying figures and imitating finger postures, as well as reading sentences (Fig. 2). On Raven's Colored Progressive Matrices, he tended to point to left-sided pictures, and never pointed to right-sided ones. His neglect did not improve when
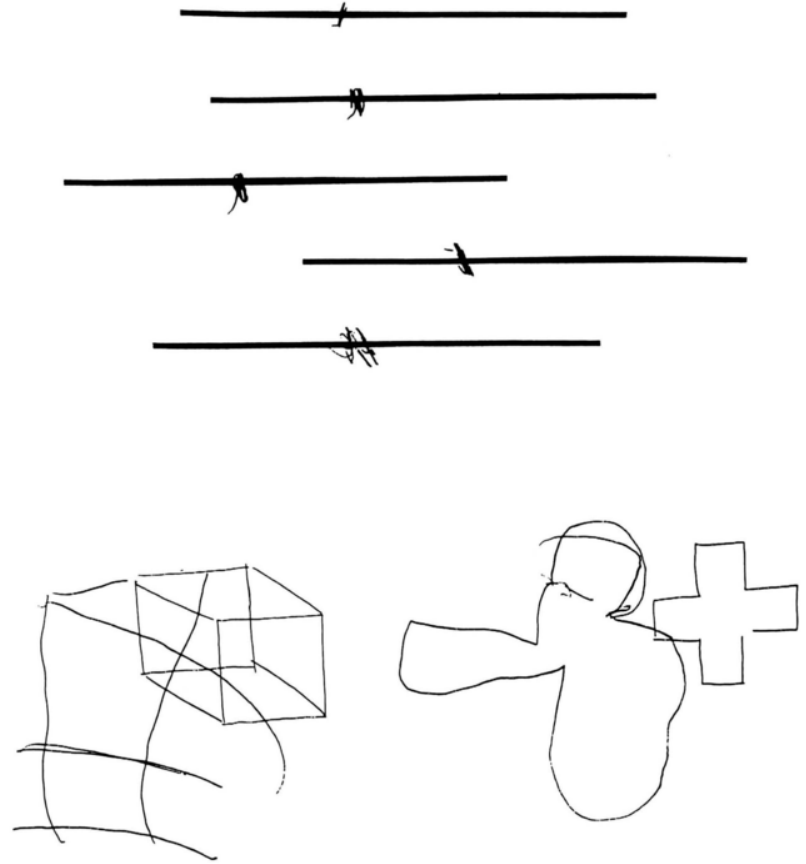

FIG 2. Line bisection and copying figures showed distinct right hemineglect.

the stimuli were presented in the left visual field. We believe that his neglect cannot be attributed to the visual field deficit although we did not assess any representational form of neglect. Constructional disturbance was apparent in the Block Design subtest of WAIS-R. Auditory and tactile extinction of a right-

124 Behavioural Neurology . Vol 7 . 1994 
TABLE II. Reported patients with left-sided lesions who showed non-dominant hemisphere signs and no aphasia

\begin{tabular}{|c|c|c|c|c|c|c|}
\hline & $\begin{array}{c}\text { Taylor et al. } \\
\text { (1979) }\end{array}$ & $\begin{array}{c}\text { Kellar et al. } \\
\text { (1985) }\end{array}$ & $\begin{array}{c}\text { Junqué et al. } \\
\text { (1986) }\end{array}$ & $\begin{array}{c}\text { Caramazza et al. } \\
(1990)\end{array}$ & $\begin{array}{c}\text { Maeshima et al. } \\
\text { (1992) }\end{array}$ & $\begin{array}{l}\text { Present } \\
\text { patient }\end{array}$ \\
\hline Handedness & Mixed & Right & Right & Left & Right & Right \\
\hline Familial sinistrality & + & - & - & N.D. & + & + \\
\hline Extent of lesion & T-P & F-T-P & F-T-P & P (subcortical) & F-T-P & T-P \\
\hline \multicolumn{7}{|l|}{ Neurobehavioural findings } \\
\hline Langage assessment & Token: 21/22 & Token: $29 / 36$ & $\begin{array}{l}\text { Token: } 35 / 36 \\
\text { BNT. } 55 / 60\end{array}$ & Token: $33.5 / 36$ & Normal SLTA & WAB AQ: 93.8 \\
\hline & & & & & $\begin{array}{l}\text { in speech and } \\
\text { hearing }\end{array}$ & \\
\hline Agraphia & Spatial & N.D. & Apraxic & Spatial & Aphasic & Spatial \\
\hline Ideomotor apraxia & N.D. & N.D. & + & N.D. & - & - \\
\hline Right hemineglect & + & + & + & + & + & + \\
\hline Constructional apraxia & + & + & + & - & + & + \\
\hline Sensory extinction & N.D. & N.D. & + & + & N.D. & + \\
\hline Motor impersistence & N.D. & N.D. & N.D. & N.D. & N.D. & - \\
\hline Prosopagnosia & + & N.D. & N.D. & N.D. & N.D. & - \\
\hline $\begin{array}{l}\text { Anosognosia or } \\
\text { anosodiaphoria }\end{array}$ & N.D. & N.D. & N.D. & N.D. & + & + \\
\hline Affective deficit & + & + & + & N.D. & N.D. & + \\
\hline
\end{tabular}

+, positive; - , negative; N.D., not described; T-P, temporo-parietal; F-T-P, fronto-temporo-parietal; P, parietal; Token, Token Test; BNT, Boston Naming Test; SLTA, Standard Language Test for Aphasia (Takeda, 1977); WAB, Western Aphasia Battery; AQ, Aphasia Quotient.

sided stimulus was present on double-simultaneous stimulation. Motor impersistence was not demonstrated in the eye closure and tongue protrusion procedure.

Anosodiaphoria for the right hemiparesis was apparent in his daily activities. For example, he often stood up from a wheelchair with no assistance, as if he had no motor weakness, and almost fell to the right side. When asked, however, he did not deny the presence of the hemiparesis verbally. Nursing staff recorded his affective state as "flat" and "indifferent". He and his family reported no disturbance in his face recognition ability, though we did not assess this formally.

His neurological and neurobehavioural states did not change during the 2 months of his hospital stay.

\section{DISCUSSION}

This right-handed patient with a large left temporoparietal lesion showed persistent right hemispatial neglect, spatial agraphia, constructional apraxia, auditory and tactile extinction, anosodiaphoria and affective change over 5 years after the stroke onset. On the other hand, aphasia and ideomotor apraxia were never observed.

Right hemispatial neglect, if present, is usually slight in degree and rarely persists for months in leftbrain-damaged patients with normal laterality of cognitive functions (Weintraub and Mesulam, 1989). This patient's hemineglect, however, was distinct in many tasks and persisted for 5 years. We also observed spatial agraphia (Hécaen and Marcie, 1974), anosodiaphoria for hemiparesis (Babinski, 1914) and affective change with indifference reactions (Gainotti, 1972), which usually occur after right hemispheric damage. These findings suggest the affected left hemisphere of this patient functioned as non-dominant. Constructional apraxia and persistent sensory extinction may occur after damage to either hemisphere, but are more frequent in right-sided injury (Benton, 1989; De Renzi et al., 1984). We interpreted his low scores in digit span and MMSE as a sign of confusional state, which may be associated with non-dominant brain lesion (Mesulam et al., 1976; Mori and Yamadori, 1987) and persist for years (Mullaley et al., 1982). Thus, these signs in this patient are consistent with non-dominant hemispheric injury.

Right brain damage may also cause motor impersistence or prosopagnosia, both of which were absent in the patient. A right anterior lesion is said to be responsible for motor impersistence (Kertesz et al., 1985) and right occipital damage for prosopagnosia (Landis et al., 1988). We believe that the patient's temporo-parietal lesion spared these areas.

Thus, we conclude that this patient had a reversed laterality of cognitive functions and showed a crossed non-dominant hemisphere syndrome. Table II summarizes reported patients with left-sided lesions who 
showed non-dominant hemisphere signs and were described as having no aphasia. All of them had a diffuse cortical infarction in the territory of the left middle cerebral artery except the patient of Caramazza and Hillis (1990). Taylor and Solomon (1979) and Kellar and Levick (1985) did not mention ideomotor apraxia, which was observed in the patient of Junqué et al. (1986). Most reports contain no mention of some non-dominant hemisphere signs, such as sensory extinction, motor impersistence, anosognosia or anosodiaphoria. On the other hand, we found most of the non-dominant hemisphere signs in our patient, but no ideomotor apraxia or aphasia.

The patient had two left-handed children, though he himself was right-handed. Most patients with left handedness or family history of sinistrality have normal or bilateral presentation of cognitive functions (Hécaen et al., 1981; Bryden, 1988). On the other hand, this patient showed an almost complete non-dominant hemisphere syndrome, and absence of language dysfunction. These facts suggest that he had a discrete and reversed lateralization of cognitive function.

\section{REFERENCES}

Babinski MJ (1914) Contribution à l'étude des troubles mentaux dans l'hémiplégie organique cérébrale (anosognosie). Revue Neurologique, 27, 845-848.

Benton A (1989) Constructional apraxia. In: Handbook of Neuropsychology, Vol. 2 (Eds F. Boller and J. Grafman), pp. 387-394. Elsevier, Amsterdam.

Bryden MP (1988) Cerebral specialization: clinical and experimental assessment. In: Handbook of Neuropsychology, Vol. 1 (Eds F Boller and J Grafman), pp. 143-159. Elsevier, Amsterdam.

Caramazza A and Hillis AE (1990) Levels of representation, co-ordinate frames and unilateral neglect. Cognitive Neuropsychology, 7, 391-445.

De Renzi E, Gentilini M and Pattacini F (1984) Auditory extinction following hemisphere damage. Neuropsychologia, 22, 733-744.

Gainotti G (1972) Emotional behavior and hemispheric side of lesion. Cortex, 8, 41-55.

Gainotti G (1989) Disorders of emotions and affect in patients with unilateral brain damage. In: Handbook of Neuropsychology, Vol. 3 (Eds F Boller and J Grafman), pp. 345-361. Elsevier, Amsterdam.

Hécaen H and Marcie P (1974) Disorders of written language following right hemisphere lesions: Spatial dys- graphia. In: Hemisphere Function in the Human Brain (Eds J Beaumont and S Dimond), pp. 345-366. Paul Elek, London.

Hécaen H, De Agostini M. and Monzon-Montes A (1981) Cerebral organization in left-handers. Brain and Language, 12, 261-284.

Hier DB, Mondlock J and Caplan LR (1983) Behavioral abnormalities after right hemisphere stroke. Neurology, 33, 337-344.

Junqué C, Litvan I and Vendrell P (1986) Does reversed laterality really exist in dextrals? A case study. Neuropsychologia, 24, 241-254.

Kellar LA and Levick SE (1985) Reversed hemispheric lateralization of cerebral function: A case study. Cortex, 21, 469-476.

Kertesz A, Nicholson I, Cancelliere A, Kassa K and Black SE (1985) Motor impersistence: A right-hemisphere syndrome. Neurology, 35, 662-666.

Landis T, Regard M, Bliestle A and Kleihues P (1988) Prosopagnosia and agnosia for noncanonical views. An autopsied case. Brain, 111, 1287-1297.

Maeshima S, Kajiwara T, Dohi N, Yoshimura M, Nakagawa T and Shigeno K (1992) "Left unilateral agraphia with right hemiparesis" after occlusion of the left middle cerebral artery. Brain and Nerve, 44, 661-666 (in Japanese).

Mesulam M-M, Waxman SG, Geschwind N and Sabin TD (1976) Acute confusional states with right middle cerebral artery infarctions. Journal of Neurology, Neurosurgery and Psychiatry, 39, 84-89.

Mori E and Yamadori A (1987) Acute confusional state and acute agitated delirium. Occurrence after infarction in the right middle cerebral artery territory. Archives of Neurology, 44, 1139-1143.

Mullaley W, Huff K, Ronthal M and Geschwind N (1982) Chronic confusional state with right middle cerebral artery occlusion. Neurology, 32, 496.

Takeda K (1977) Standard language test of aphasia: detailed description of construction of aphasia test in Japanese. Shinkei Kenkyu no Shinpo, 3, 450-458 (in Japanese).

Taylor HG and Solomon JR (1979) Reversed laterality: A case study. Journal of Clinical Neuropsychology, 1, 311322.

Weintraub S and Mesulam M-M (1989) Neglect: hemispheric specialization, behavioral components and anatomical correlates. In: Handbook of Neuropsychology, Vol. 2 (Eds F Boller and J Grafman), pp. 357-374. Elsevier, Amsterdam.

(Received 28 June 1994; accepted as revised 20 October 1994) 


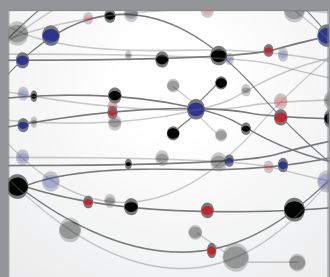

The Scientific World Journal
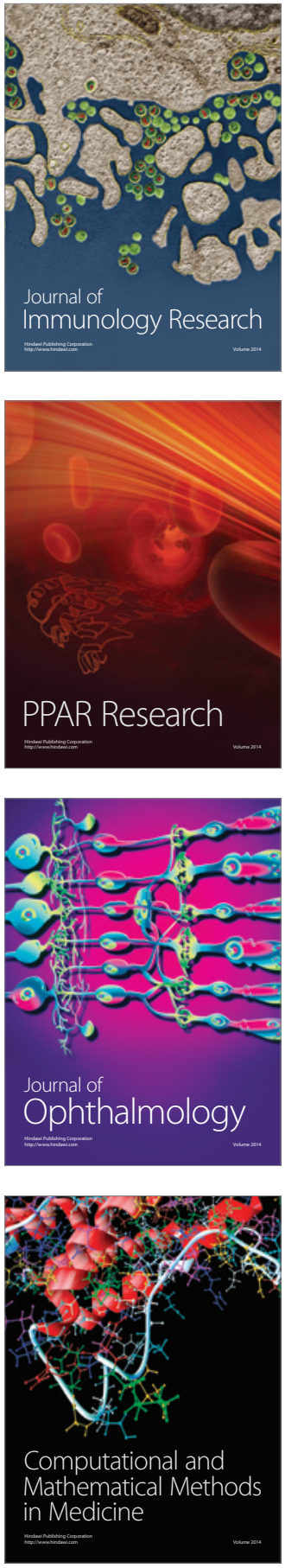

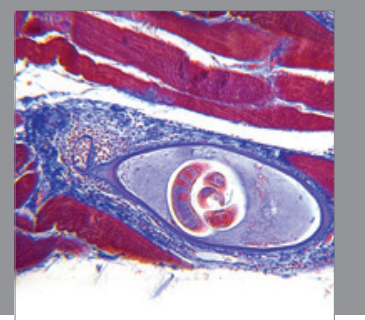

Gastroenterology

Research and Practice
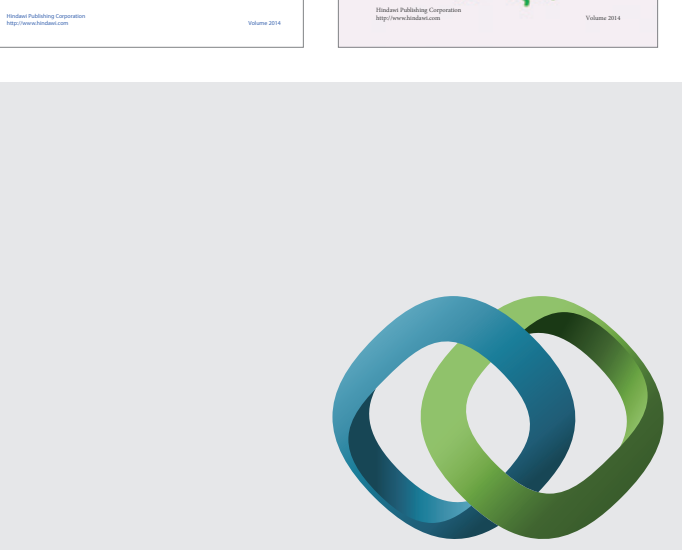

\section{Hindawi}

Submit your manuscripts at

http://www.hindawi.com
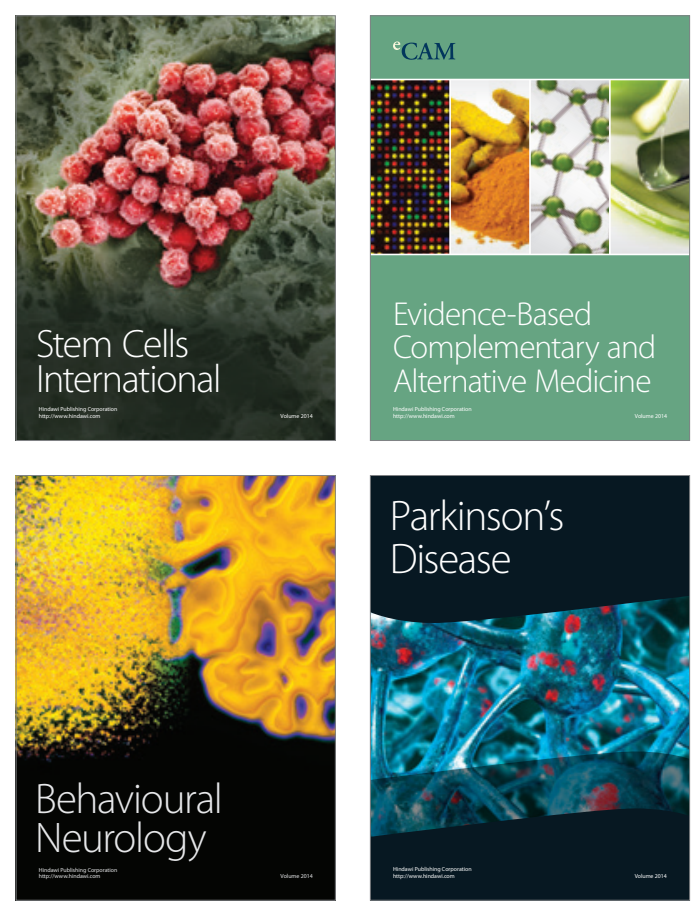

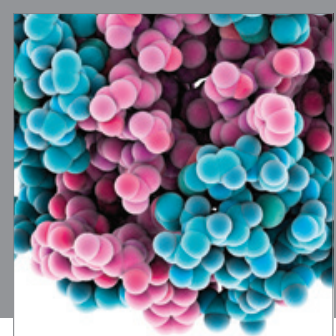

Journal of
Diabetes Research

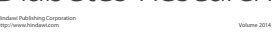

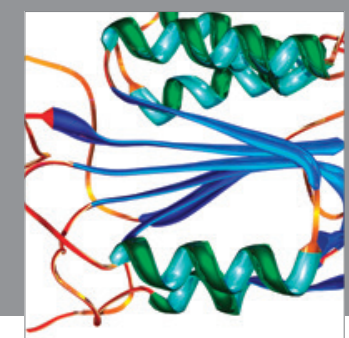

Disease Markers
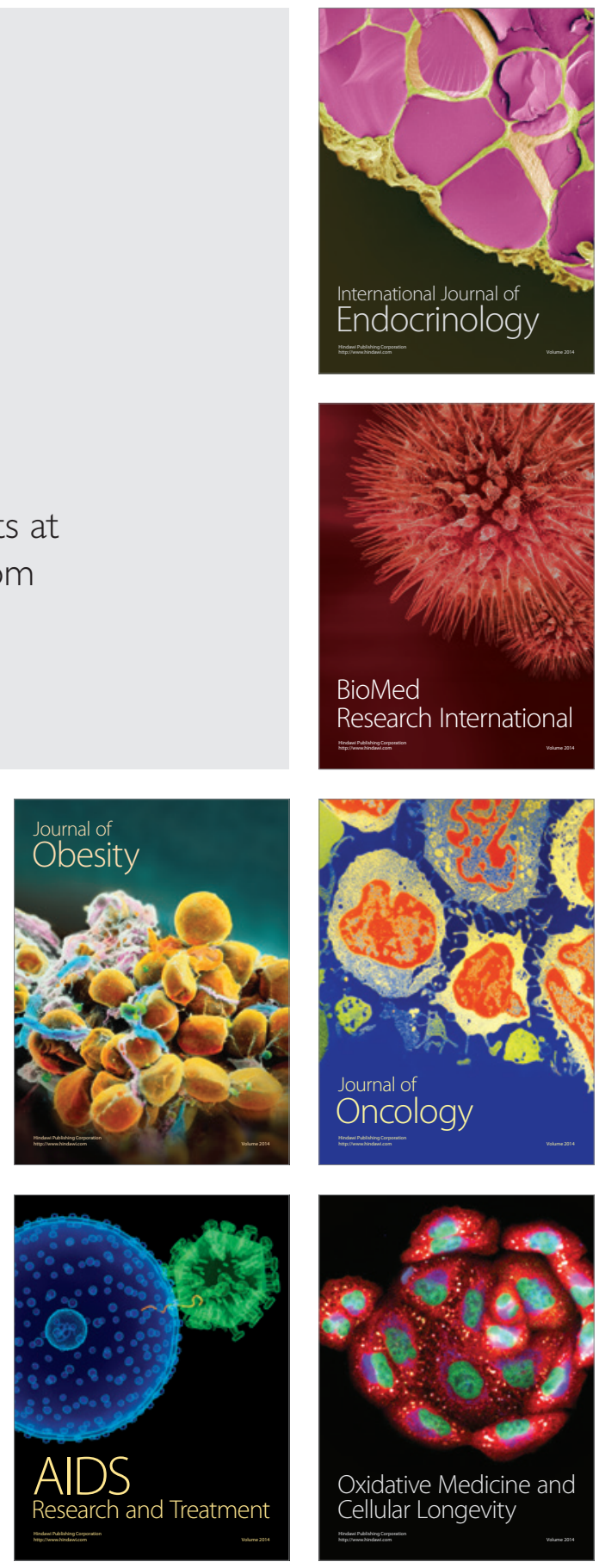